\title{
INTRAVENOUS GRANISETRON, ONDANSETRON AND METOCLOPRAMIDE IN THE PREVENTION AND TREATMENT OF POST OPERATIVE NAUSEA AND VOMITING AFTER LAPAROSCOPIC CHOLECYSTECTOMY - A COMPARATIVE STUDY
}

\author{
Sabina Yeasmeen ${ }^{1}$, Rubina Yasmin ${ }^{2}$, AKM Akhtaruzzaman ${ }^{3}$, UH Shahera Khatun ${ }^{4}$
}

\section{SUMMARY:}

Postoperative nausea and vomiting are the common morbidity after general anaesthesia and surgery ${ }^{1}$. One of the essential goals of anaesthetic management is to prevent postoperative nausea and vomiting. The consequence of prolonged postoperative nausea and vomiting (PONV) ranges from unexpected admission of day patients with its economic implications to physical, metabolic and psychological effects on the patients which slow their recovery and reduced their confidence in future surgery and anaesthesia ${ }^{2}$.

The present study was designed to compare the efficacy of Granisetron with that of Ondansetron and Metoclopramide in the treatment and prevention of postoperative nausea and vomiting after laparoscopic cholecystectomy. This study was also done to observe the incidence of nausea and vomiting in the postoperative period, to observe the requirement of rescue antiemetic, to find out the haemodynamic stability, saturation of arterial oxygen in these groups of subject and to detect the patients satisfaction by verbal rating scale after 24 hours of surgery.

A total number of 90 patients, sex female, age range 30-50 years undergoing laparoscopic cholecystectomy were selected. They were equally divided into three groups of 30 patients. They received a standard general anaesthesia. Group I received injection Granisetron (1mg), Group II received injection Ondansetron (8mg), Group III received injection Metoclopramide (10mg) 10 minutes before reversal of anaesthesia. Postoperative analgesia was provided with injection pethidine $(1.5 \mathrm{mg} / \mathrm{kg} / \mathrm{bd}$.wt.) intramuscularly 8 hourly.
In the recovery room occurrence of nausea and vomiting was assessed for 24 hours. The incidence of emesis free (no nausea) was significantly higher in patients who received Ganisetron (90.0\%, 27/ $30)$ than in those who received Ondansetron [(66.7\%, 20/30), $p=0.028]$ or metoclopramide [(40.0\%, 12/30), $p=0.000]$.The incidence of vomiting free was significantly higher in patients who received Granisetron (93.3\%, 28/30) than in those who received Ondansetron [73.3\%, 22/30), $p=0.037$ ] or Metoclopramide [46.7\%, 14/30), $p=0.000]$. Granisetron was associated with greater patients' satisfaction than Ondansetron and Metoclopramide $40 \%, 20 \%$ and $10 \%$ of patients respectively. No need for another rescue antiemetic medication was achieved in $86.7 \%$ of patients with granisetron, $70.60 \%$ with Ondansetron and $53.3 \%$ with Metoclorpramide. The haemodynamic variables, heart rate, blood pressure, $\mathrm{SpO} \mathrm{O}_{2}$ were recorded carefully in different time intervals. There was no significant difference among the study.

So, it can be concluded that Granisetron is more effective than Ondansetron and Metoclopramide in the prevention and treatment of postoperative nausea and vomiting after laparoscopic cholecystectomy.

\section{INTRODUCTION:}

Nausea is a subjective phenomenon of unpleasant wave like sensation experienced in the back of throat and/or the epigastrium that may or may not culminate in vomiting. Vomiting is the forceful expulsion of the contents of the stomach, duodenum or jejunum through the oral cavity. Retching is gastric and esophageal movement of vomiting without expulsion of vomitus and is also referred to

1. Resident, Department of Anaesthesia, Analgesia \& Intensive Care Medicine, BSMMU, Dhaka

2. Assistant Professor, Department of Anaesthesiology \& ICU, DMCH, Dhaka

3. Associate Professor Department of Anaesthesia, Analgesia \& Intensive Care Medicine, BSMMU, Dhaka

4. Professor \& Head, Department of Anaesthesiology \& ICU, DMCH, Dhaka 
as 'dry heaves' 3 . Nausea, vomiting and retching are among the most common postoperative complaints and can occur after general or regional anaesthesia ${ }^{4}$.

The aetiology of PONV are complex and multi factorial and includes factors related to the characteristics of the patients, type of surgery, type of anaesthetics agents and post operative condition. It is also related to the haemodynamic instability (heart rate, blood pressure), arterial oxygen saturation, respiration, pain and sedation ${ }^{3}$ and can expose the subject to an increased risk of pulmonary aspiration of vomitus if airway reflexes are depressed from the residual effects of anaesthetic and analgesic drugs ${ }^{5}$.

Laparoscopic cholecystectomy is associated with a high incidence of $65 \%$ postoperative nausea and vomiting ${ }^{3}$. In laparoscopic cholecystectomy due to creation of pneumoperitonium has direct effect on postoperative nausea and vomiting and due to instrumental manipulation of abdominal viscera that may cause the release of humoral substances including 5-HT which may stimulate $5-\mathrm{HT}_{3}$ receptor in the afferent vagus nerves, triggering the emetic reflex (CTZ) chemoreceptor trigger zone located in the area postrema outside the brain barrier.

Pharmacologic approaches (antihistamines, butyrophenones, dopamine receptor antagonists) have been investigated for the prevention and treatment of PONV, but such undersirable adverse effects as excessive sedation, restlessness, dystonic reactions and extrapyramidal symptoms have been noted $^{3}$.

Granisetron, $5-\mathrm{HT}_{3}$ receptor antagonist, is more potent and has longer lasting effects against chemotherapy-induced emesis than ondansetron. It is effective for the prevention of $\mathrm{PONV}^{6}$. It has 5 to 10 times greater affinity for the $5-\mathrm{HT}_{3}$ receptor than ondansetron and has twice the duration of action ${ }^{7}$. Ondansetron, a selective 5-hydroxytryptamine (5$\mathrm{HT}_{3}$ ) receptor antagonist, is effective for the prevention of PONV (Mckenzie R et al. 1993) and for the treatment of established $\mathrm{PONV}^{8}$. Metoclopramide is a procainamide derivative and a benzamide prokinetic agent with dual sites of action, blocking $\mathrm{D}_{2}$ receptors in the periphery (G.I. tract) and centrally (CTZ and area postrema. Vomiting Centre). It is effective for the treatment of postoperative nausea and vomiting ${ }^{9}$. It has short duration of action (1 to 2 hours) and less potent.
Postoperative nausea and vomiting are the common morbidity after general anaesthesia. So in the present study the efficacy of granisetron was compared with that of ondansetron and metoclopramide in the prevention of PONV after laparoscopic cholecystectomy. For this, the study was designed to assess the efficacy of granisetron over ondansetron and metoclopramide by observing the incidence of nausea and vomiting, requirement of rescue antiemetic in postoperative period and also to detect the patient's satisfaction by verbal rating scale after 24 hours of surgery.

\section{MATERIALS AND METHODS:}

This randomized prospective clinical study was carried out in the Department of Anaesthesiology and ICU, Dhaka Medical College Hospital, Dhaka during the period of January 2005 to December 2006. Female patients aged between $30-50$ years with ASA grade I and II and scheduled for laparoscopic cholecystectomy under general anaesthesia were recruited in this study. Females with known history of hypersensivity to study drugs, gastrointestinal diseases, who had taken antiemetics within 24 hours before surgery, receiving hormonal therapy and pregnant and menstruating patients were excluded from this study.

After recruitment, patients were randomly divided into three groups, thirty patients in each group. Group-I received inj. granisetron(1 $\mathrm{mg})$ intravenously, Group-II received inj. ondansetron (8mg) intravenously and group-III (control group) received inj. metoclopramide $(10 \mathrm{mg})$ intravenouslyall 10 minutes before reversal of anaesthesia. Patients data were collected in prescribed forms containing patients particulars, preoperative baseline (pulse, blood pressure-systolic and diastolic blood pressue, SPO2) parameters, preoperative and postoperative parameters including nausea, vomiting, patients satisfaction by 4 points VRS(Verbal Rating Scale) and use of rescue antiemetics. After preoxygenation for 3-5 minutes with $100 \%$ oxygen, induction of anaesthesia was done with inj. Fentanyl (1mg/kg body weight) and inj. Thiopentone sodium $(5 \mu \mathrm{g} / \mathrm{kg}$ body wt.) and endotracheal intubation was done after giving inj. suxamethonium $(1.5 \mathrm{mg} / \mathrm{kg}$ body wt.).Maintenance of anaesthesia with $\mathrm{N}_{2} \mathrm{O} 70 \%, \mathrm{O}_{2} 30 \%$ and Halothane $0.5-1 \%$ with long acting nondepolarizing neuromuscular blocking agent Vecuronium $(0.1 \mathrm{mg} /$ $\mathrm{kg}$ body wt.).Incremental dose of Fentanyl (0.3-0.4 micro $\mathrm{gm} / \mathrm{kg}$ body wt.) was given if required. 
Intraoperative fluid was maintained with Hartmann's so; ution or normal saline. Ten minutes before reversal of anaesthesia each group of patient's received intravenously. Group-I Inj. Granisetron (1mg), Group-II Inj.Ondansetron (8mg);Group-III (Control group) Inj. Metaclopramide (10mg). Time of surgery was within $1{ }^{1 /}$ hour.Residual effect of neuromuscular blocking agent was reversed by injection neostigmine $(.04 \mathrm{mg} / \mathrm{kg} / \mathrm{bw})$ and injection atropine $(0.02 \mathrm{mg} / \mathrm{kg} / \mathrm{b} . \mathrm{w}$.$) and tracheal extubation$ performed. Patients were monitored preoperatively and postoperatively.

In postoperative room proper hydration maintained. Analgesia maintained by injection pethidine $(1.5 \mathrm{mg} /$ $\mathrm{kg} / \mathrm{bw}$.) given intramuscularly 8 hourly in each patient, on patient demanded injection ketorolac and (30 mg) given intramuscularly. The 24 hours study period started upon entry to the postoperative room. Patient was observed at 30 minutes, 1 hour, 2 hours, 4 hours, 8 hours, 16 hours and 24 hours after recovery. In this period haemodynamic parameters (pulse, systolic and diastolic blood pressure), arterial oxygen saturation, the number and time of nausea and vomiting and rescue antiemetic treatment were recorded.Injection antiemetic was given according to the patient needs. Patient satisfaction was recorded by 4 points verbal rating scale 24 hours after recovery.

\section{STATISTICAL ANALYSIS}

All the variables were expressed as mean $\pm \mathrm{SD}$. One way ANOVA and Pearson's Chi-square $\left(\mathrm{X}^{2}\right)$ test were done as the tests of significance whenever applicable to compare the mean of different groups. The statistical analysis was done by using SPSS programme. P-value $<0.05$ was considered as significant.

\section{RESULTS}

Observation of the present study was analyzed in the light of comparison among each subject groups. Each group having $n=30$. All results were expressed as mean $\pm \mathrm{SEM}$ or in frequencies as applicable. The groups became statistically matched for age $(\mathrm{P}=0.948)$, weight $(\mathrm{P}=0.908)$. There was no significant difference among the study groups.

Table-I

Age, body weight different study groups $(n=90)$.

\begin{tabular}{lcccc}
\hline Variable & $\begin{array}{c}\text { Group-I } \\
(\mathrm{n}=30)\end{array}$ & $\begin{array}{c}\text { Group-II } \\
(\mathrm{n}=30)\end{array}$ & $\begin{array}{c}\text { Group-III } \\
(\mathrm{n}=30)\end{array}$ & P value \\
\hline Age (years) & $37.3 \pm 2.06$ & $36.7 \pm 1.82$ & $37.5 \pm 1.49$ & $0.948^{\text {ns }}$ \\
Weight(kg) & $53.5 \pm 1.38$ & $54.4 \pm 1.90$ & $54.4 \pm 1.88$ & $0.908^{\text {ns }}$ \\
\hline
\end{tabular}

Values are expressed as Mean \pm SD. (Within parenthesis are percentages over column total). Age and weight analysis done by ANOVA test. Value are regarded significant if $\mathrm{P}<0.05$.

Group-I: Granisetron

Group-II: Ondansetron

Group-III: Metoclopramide

Figure in parentheses indicates ranges, ns $=$ not significant, $n=$ number of subjects.

Table-II

Incidence of nausea between different study groups $(n=90)$.

\begin{tabular}{lccc}
\hline Groups & $\mathrm{n}$ & No Nausea & Nausea \\
\hline I & 30 & $27(90.0 \%)$ & $3(10.0 \%)$ \\
II & 30 & $20(66.7 \%)$ & $10(33.3 \%)$ \\
III & 30 & $12(40.0 \%)$ & $18(60.0 \%)$ \\
\hline Total & 90 & $59(62.2 \%)$ & $31(34.4 \%)$ \\
\hline
\end{tabular}

Statistical analysis:

\begin{tabular}{lcc} 
Groups & $\mathrm{X}^{2}$ value & P value \\
I vs II & 4.81 & $0.028^{*}$ \\
I vs III & 16.48 & $0.000^{* * *}$ \\
II vs III & 4.29 & $0.0038^{*}$ \\
\hline
\end{tabular}

The incidence of nausea in different study groups are shown in number and percentage in table-II.

The incidence of nausea was 10\% in group-I, 33.3\% in group-II \& $60 \%$ in group-III respectively. The difference was statistically significant between group I vs group II $(p=<0.05)$. The difference was statistically significant between group I vs Group III ( $p<0.001)$. And also between groups II vs. group III it was statistically significant $(\mathrm{p}<0.05)$.

The incidence of no nausea in group-I 90\%, groupII $66.7 \%$ and group-III $40 \%$. Incidence of nausea group-I 10\%, group-II $33.3 \%$ and group-III 60\%. 


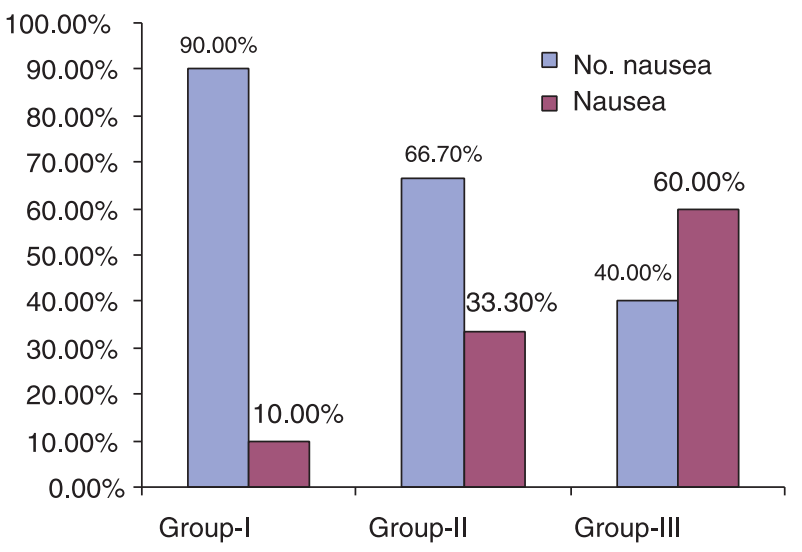

Fig. 1: Incidence of nausea in different study group $(n=90)$.

Table- III

Incidence of vomiting in different study groups $(n=90$.

\begin{tabular}{lccc}
\hline Groups & $\mathrm{n}$ & No. vomiting & Vomiting \\
\hline I & 30 & $28(93.3 \%)$ & $2(6.70 \%)$ \\
II & 30 & $22(73.3 \%)$ & $8(26.7 \%)$ \\
III & 30 & $14(46.7 \%)$ & $16(53.3 \%)$ \\
Total & 90 & $64(71.1 \%)$ & $26(28.9 \%)$
\end{tabular}

Statistical analysis:

Groups $\mathrm{X}^{2}$ value Pvalue

I (vs) II $4.32 \quad 0.037^{*}$

I (vs) III $15.56 \quad 0.000^{* * *}$

II (vs) III $4.44 \quad 0.0035^{*}$

The incidence of vomiting in different study groups is shown in number and percentage in table-III.
The incidence of vomiting was $6.7 \%$ in group-I, $26.6 \%$ in group-II \& $53.3 \%$ in group-III respectively. The difference was statistically significant between group I vs group II $(p=<0.05)$. There was statistically significant difference between group I vs Group III ( $p<0.001)$. The difference between group II vs group III was statistically significant $(\mathrm{p}<0.05)$.

The incidence of no vomiting group-I $93.30 \%$, groupII $73.30 \%$ and group-III $46.70 \%$. Incidence of vomiting group-I $6.70 \%$, group-II $26.70 \%$ and groupIII $53.30 \%$.

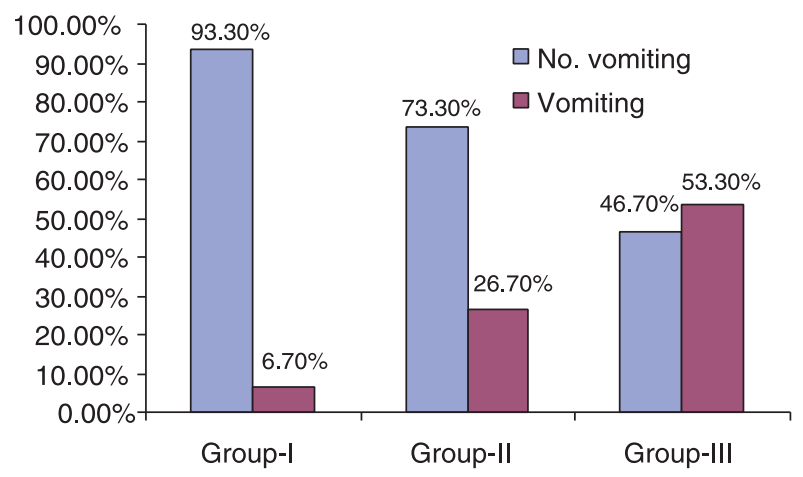

Fig. 2: Incidence of vomiting in different study group $(n=90)$.

Overall patient satisfaction by verbal rating scale (VRS):

Overall patient satisfaction in 24 hours in post operative period by verbal rating scale (VRS). After 24 hours overall patient satisfaction was assessed. In group-I, 1 patients rated "not effective at all", 6 "moderate effective", 11 "effective" and 12 "excellent". In group II, 5 patients rated "not effective at all", 10 "moderately effective", 9 "effective" and 6 "excellent". In group-III, 7 patients rated "not effective at all", 13 "moderately effective", 7 "effective" and 3 "excellent".

Table-IV

Satisfactory level by four point verbal rating scale.

\begin{tabular}{lcccccc}
\hline & Group-I(n=30) & Group-II(n=30) & Group-III(n=30) & Total (n=90) & $\chi^{2}$-value & P-value \\
\hline Not effective at all & 1 & 5 & 7 & 13 & & \\
& $3.3 \%$ & $16.7 \%$ & $23.3 \%$ & $14.4 \%$ & & \\
Moderately effective & 6 & 10 & 13 & 29 & & \\
& $20.0 \%$ & $33.3 \%$ & $43.3 \%$ & $32.2 \%$ & & \\
Effective & 11 & 9 & 7 & 27 & 13.75 & $0.032^{\mathrm{s}}$ \\
& $36.7 \%$ & $30.0 \%$ & $23.3 \%$ & $30.0 \%$ & & \\
Excellent & 12 & 6 & 3 & 21 & \\
Total & $40.0 \%$ & $20.0 \%$ & $10.0 \%$ & $23.3 \%$ & \\
& 30 & 30 & 30 & 90 & \\
& $100.0 \%$ & $100.0 \%$ & $100.0 \%$ & $100.0 \%$ & & \\
\hline
\end{tabular}


Rescue antiemetic in different study groups

The incidence of rescue antiemetic in different study groups are shown in number and percentage in Table-V.

The incidence of rescue antiemetic was $13.3 \%$ in group-I, $30.0 \%$ in group-II \& $46.7 \%$ in group-III. The different study among the groups was statistically significant $(p<0.05)$.

\section{Heart rate (beats/min) variation in different study}

The mean $\pm \mathrm{SD}$ values of the heart rate $(\mathrm{HR})$ in preoperative period were in group-I $(88.0 \pm 1.6) / \mathrm{min}$, in group-II (89.1 \pm 3.1$) / \mathrm{min}$, in group-III $(87.8 \pm 1.5) /$ min. The mean of heart rate was not statistically significant ( $p>0.05$ ) (Table-VI).

The mean $\pm \mathrm{SD}$ values of heart rate (HR) during intraoperaitve period were in group-I - (88.8 \pm 2.4$)$ / $\mathrm{min}$, in group-II $(91.8 \pm 1.4) / \mathrm{min}$, group-III $(86.9 \pm 1.8)$ / min. The mean of heart rate was not statistically significant $(\mathrm{p}>0.05)$ (Table-VI).

The mean of heart rate (HR) at 30 minutes after recovery ( $p>0.05), 1$ hour after recovery $(p>0.05), 2$ hours after recovery ( $>0.05), 4$ hours after recovery $(p>0.05), 8$ hours after recovery $(p>0.05), 16$ hours after recovery $(p>0.05)$ and 24 hours after recovery were not statistically significant $(p>0.05)$ (Table-VI).

Systolic blood pressure (SBP, $\mathrm{mmHg}$ ) in different study groups are shown in Table-VII.

The Mean \pm SD values of systolic blood pressure (BP) in preoperative period were in Group-I(119.5 \pm 3.3$) / \mathrm{mm}$ of $\mathrm{Hg}$, in Group-II $(118.0 \pm 3.9) / \mathrm{mm}$ of $\mathrm{Hg}$, Group-III (121.0 \pm 3.9$) / \mathrm{mm}$ of $\mathrm{Hg}$. The mean of systolic blood pressure was not statistically significant ( $p>0.05)$ (Table-VII).

The Mean \pm SD values of systolic blood pressure (BP) during intraoperative period were in Group-I(127.0 \pm 4.8$) / \mathrm{mm}$ of $\mathrm{Hg}$, in Group-II $(135.0 \pm 2.4) / \mathrm{mm}$ of $\mathrm{Hg}$, Group-III (130.0 \pm 2.2$) / \mathrm{mm}$ of $\mathrm{Hg}$. The mean of systolic blood pressure was not statistically significant ( $p>0.05)$ (Table-VII).

The Mean of systolic blood pressure (BP) at 30 minutes after recovery $(p>0.05), 1$ hour after recovery $,(p>0.05), 2$ hours after recovery $(p>0.05)$, 4 hours after recovery ( $>0.05), 8$ hours after recovery $(p>0.05), 16$ hours after recovery $(p>0.05)$ and 24 hours after recovery were not statistically significant $(\mathrm{p}>0.05)$.

Table-V

Rescue antiemtic in different groups $(n=90)$.

\begin{tabular}{lcccccc}
\hline & Group-I $(\mathrm{n}=30)$ & Group-II $(\mathrm{n}=30)$ & Group-III $(\mathrm{n}=30)$ & Total $(\mathrm{n}=90)$ & $\chi^{2}$-value & P-value \\
\hline No & 26 & 21 & 16 & 26 & & \\
& $86.7 \%$ & $70.0 \%$ & $53.3 \%$ & $86.7 \%$ & & \\
Yes & 4 & 9 & 14 & 4 & 7.937 & $0.02^{\mathrm{s}}$ \\
& $13.3 \%$ & $30.0 \%$ & $46.7 \%$ & $13.3 \%$ & & \\
Total & 30 & 30 & 30 & 30 & \\
& $100.0 \%$ & $100.0 \%$ & $100.0 \%$ & $100.0 \%$ & \\
\hline
\end{tabular}

Table-VI

Changes in heart rate in different study groups $(n=90)$.

\begin{tabular}{lccccccccc}
\hline & Pre & Intra & $30 \mathrm{~min}$ & $1 \mathrm{hr}$ & $2 \mathrm{hr}$ & $4 \mathrm{hr}$ & $8 \mathrm{hr}$ & $16 \mathrm{hr}$ & $24 \mathrm{hr}$ \\
\hline Group-I(n=30) & $88.0 \pm 1.6$ & $88.8 \pm 2.4$ & $87.8 \pm 1.6$ & $89.2 \pm 1.8$ & $90.2 \pm 1.7$ & $89.0 \pm 2.2$ & $91.7 \pm 1.9$ & $88.6 \pm 1.7$ & $82.8 \pm 1.2$ \\
Group-II(n=30) & $89.1 \pm 3.1$ & $91.8 \pm 1.4$ & $91.4 \pm 2.3$ & $87.6 \pm 1.6$ & $87.6 \pm 1.6$ & $92.8 \pm 1.3$ & $96.6 \pm 1.9$ & $85.0 \pm 0.8$ & $84.6 \pm 1.2$ \\
Group-III(n=30) & $87.8 \pm 1.5$ & $86.9 \pm 1.8$ & $88.6 \pm 1.6$ & $87.8 \pm 1.4$ & $85.6 \pm 0.6$ & $90.0 \pm 1.8$ & $93.6 \pm 2.2$ & $87.2 \pm 1.3$ & $82.2 \pm 0.7$ \\
F-value & 0.10 & 1.731 & 1.027 & 0.29 & 2.678 & 1.209 & 1.546 & 1.921 & 1.45 \\
P-value & $0.902^{\mathrm{ns}}$ & $0.183^{\mathrm{ns}}$ & $0.363^{\mathrm{ns}}$ & $0.748^{\mathrm{ns}}$ & $0.74^{\mathrm{ns}}$ & $0.304^{\mathrm{ns}}$ & $0.219^{\mathrm{ns}}$ & $0.153^{\mathrm{ns}}$ & $0.239^{\mathrm{ns}}$ \\
\hline
\end{tabular}


Diastolic blood pressure (DBP, $\mathrm{mmHg}$ ) in different study groups are shown in Table-VIII.

The mean \pm SD values of diastolic blood pressure (BP) in preoperative period were in Group-I(77.5 \pm 2.5$) / \mathrm{mm}$ of $\mathrm{Hg}$, in Group-II $(81.0 \pm 2.9) / \mathrm{mm}$ of $\mathrm{Hg}$, Group-III (81.0 \pm 1.9$) / \mathrm{mm}$ of $\mathrm{Hg}$. The mean of diastolic blood pressure was not statistically significant ( $p>0.05$ ) (Table-VIII),

The mean $\pm \mathrm{SD}$ values of diastolic blood pressure (BP) during intraoperative period were in Group-I(89.5 \pm 2.9$) / \mathrm{mm}$ of $\mathrm{Hg}$, in Group-II $(92.5 \pm 1.7) / \mathrm{mm}$ of $\mathrm{Hg}$, Group-III $(88.0 \pm 1.6) / \mathrm{mm}$ of $\mathrm{Hg}$. The mean of diastolic blood pressure was not statistically significant ( $p>0.05$ ) (Table-VIII).

The mean of diastolic blood pressure (BP) at 30 minutes after recovery $(p>0.05), 1$ hour after recovery $(p>0.05), 2$ hours after recovery $(p>0.05)$ , 4 hours after recovery $(p>0.05), 8$ hours after recovery ( $>0.05), 16$ hours after recovery $(p>0.05)$ and 24 hours after recovery were not statisticallysignificant $(p>0.05)$.
Arterial oxygen saturation $\left(\mathrm{SpO}_{2}\right.$ in \%) in different study groups are shown in Table-IX.

The mean $\pm \mathrm{SD}$ values of $\mathrm{SpO}_{2}$ at preoperative period were in Group-I-(97.5 $\pm 0.25 \%)$, in Group-II $(97.0 \pm 0.28) / \%$, Group-III (96.6 \pm 0.33$) / \%$. The mean of arterial oxygen saturation was not statistically significant ( $p>0.05)$ (Table-IX).

The mean $\pm \mathrm{SD}$ values of $\mathrm{SpO}_{2}$ were during intraoperative period were in Group-I-(98.1 \pm 0.36$) /$ $\%$, in Group-II (97.2 \pm 0.33$) / \%$, Group-III (97.0 \pm 0.42$) /$ $\%$. The mean of arterial oxygen saturation was not statistically significant ( $p>0.05$ ) (Table-IX).

The mean of $\mathrm{SpO}_{2}$ were at 30 minutes after recovery $(p>0.05), 1$ hour after recovery $(p>0.05), 2$ hours after recovery ( $p>0.05), 4$ hours after recovery $(p>0.05), 8$ hours after recovery $(p>0.05), 16$ hours after recovery ( $>0.05)$ and 24 hours after recovery were not statistically significant $(p>0.05)$.

Table-VII

Systolic Blood pressure (SBP, $m m H g$ ) variation in different study groups $(n=90)$.

\begin{tabular}{lccccccccc}
\hline & Pre & Intra & $30 \mathrm{~min}$ & $1 \mathrm{hr}$ & $2 \mathrm{hrs}$ & $4 \mathrm{hrs}$ & $8 \mathrm{hrs}$ & $16 \mathrm{hrs}$ & $24 \mathrm{hrs}$ \\
\hline Group-I(n=30) & $119.5 \pm 3.3$ & $127.0 \pm 4.8$ & $119.3 \pm 5.5$ & $116.5 \pm 3.3$ & $120.5 \pm 2.9$ & $115.0 \pm 6.4$ & $126.0 \pm 3.2$ & $116.5 \pm 3.3$ & $116.0 \pm 2.8$ \\
Group-II(n=30) & $118.0 \pm 3.9$ & $135.0 \pm 2.4$ & $124.3 \pm 6.0$ & $123.0 \pm 2.9$ & $122.0 \pm 3.1$ & $129.3 \pm 6.5$ & $134.5 \pm 3.9$ & $123.0 \pm 2.9$ & $120.0 \pm 3.3$ \\
Group-III(n=30) & $121.0 \pm 2.3$ & $130.0 \pm 2.2$ & $138.3 \pm 5.4$ & $124.0 \pm 1.9$ & $122.0 \pm 2.2$ & $137.3 \pm 6.6$ & $134.0 \pm 2.9$ & $124.0 \pm 1.9$ & $117.0 \pm 2.2$ \\
F-value & 0.22 & 1.47 & 3.016 & 2.19 & 0.10 & 2.970 & 1.98 & 2.19 & 0.55 \\
P-value & $0.804^{\mathrm{ns}}$ & $0.235^{\mathrm{ns}}$ & $0.056^{\mathrm{ns}}$ & $0.119^{\mathrm{ns}}$ & $0.905^{\mathrm{ns}}$ & $0.057^{\mathrm{ns}}$ & $0.144^{\mathrm{ns}}$ & $0.119^{\mathrm{ns}}$ & $0.581^{\mathrm{ns}}$ \\
\hline
\end{tabular}

Table-VIII

Diastolic Blood Pressure (DBP, $m m H g$ ) variation in different groups ( $n=90)$.

\begin{tabular}{lccccccccc}
\hline & Pre & Intra & $30 \mathrm{~min}$ & $1 \mathrm{hr}$ & $2 \mathrm{hr}$ & $4 \mathrm{hr}$ & $8 \mathrm{hr}$ & $16 \mathrm{hr}$ & $24 \mathrm{hr}$ \\
\hline Group-I(n=30) & $77.5 \pm 2.5$ & $89.5 \pm 2.9$ & $81.0 \pm 2.5$ & $78.5 \pm 2.5$ & $81.0 \pm 24$ & $84.0 \pm 1.5$ & $86.2 \pm 2.4$ & $77.5 \pm 2.2$ & $77.5 \pm 1.7$ \\
Group-II(n=30) & $81.0 \pm 2.9$ & $92.5 \pm 1.7$ & $80.5 \pm 2.7$ & $79.0 \pm 1.5$ & $76.0 \pm 2.1$ & $84.5 \pm 1.6$ & $87.3 \pm 1.0$ & $80.0 \pm 2.4$ & $79.0 \pm 1.9$ \\
Group-III(n=30) & $81.0 \pm 1.9$ & $88.0 \pm 1.6$ & $89.3 \pm 3.4$ & $83.0 \pm 1.2$ & $83.5 \pm 2.4$ & $85.7 \pm 1.6$ & $88.5 \pm 1.7$ & $85.0 \pm 2.4$ & $79.0 \pm 1.3$ \\
F-value & 0.66 & 1.10 & 2.979 & 1.82 & 2.830 & 0.297 & 0.427 & 2.618 & 0.27 \\
P-value & $0.517^{\mathrm{ns}}$ & $0.337^{\mathrm{ns}}$ & $0.056^{\mathrm{ns}}$ & $0.168^{\mathrm{ns}}$ & $0.064^{\mathrm{ns}}$ & $0.744^{\mathrm{ns}}$ & $0.654^{\mathrm{ns}}$ & $0.079^{\mathrm{ns}}$ & $0.766^{\mathrm{ns}}$ \\
\hline
\end{tabular}

\section{Table-IX}

Arterial oxygen saturation $\left(\mathrm{Sp} \mathrm{O}_{2}\right)$ variation in different study groups $(n=90)$.

\begin{tabular}{|c|c|c|c|c|c|c|c|c|c|c|c|}
\hline & Pre & Intra & & & $\min$ & $1 \mathrm{hr}$ & $2 \mathrm{hr}$ & $4 \mathrm{hr}$ & $8 \mathrm{hr}$ & $16 \mathrm{hr}$ & $24 \mathrm{hr}$ \\
\hline Group-I(n=30) & $97.5 \pm 0.25$ & $98.1 \pm 0$ & & 96.2 & \pm 0.29 & $96.6 \pm 0.24$ & $96.6 \pm 0.15$ & $95.9 \pm 0.2$ & $95.0 \pm 0.34$ & $96.3 \pm 0.12$ & $97.2 \pm 0.21$ \\
\hline Group-II(n=30) & $97.0 \pm 0.28$ & $97.2 \pm 0$ & & 96.3 & \pm 0.19 & $96.1 \pm 0.15$ & $96.3 \pm 0.17$ & $95.5 \pm 0.2$ & $95.0 \pm 0.19$ & $96.4 \pm 0.09$ & $96.7 \pm 0.24$ \\
\hline Group-III $(n=30)$ & $96.6 \pm 0.33$ & $97.0 \pm 0$. & 42 & 95.7 & \pm 0.18 & $96.7 \pm 0.17$ & $96.4 \pm 0.12$ & $95.3 \pm 0.1$ & $95.3 \pm 0.19$ & $95.9 \pm 0.23$ & $96.5 \pm 0.21$ \\
\hline 2.563 & 2.703 & 2.084 & 2.80 & & 1.07 & 2.58 & 0.48 & 2.85 & 2.723 & & \\
\hline $0.083^{\mathrm{ns}}$ & $0.073^{\mathrm{ns}}$ & $0.131^{\mathrm{ns}}$ & 0.06 & $66^{\mathrm{ns}}$ & 0.346 & $0.082^{\mathrm{ns}}$ & $0.619^{\mathrm{ns}}$ & $0.064^{\mathrm{ns}}$ & $0.071^{\mathrm{ns}}$ & & \\
\hline
\end{tabular}




\section{DISCUSSION}

Nausea and vomiting are among the most common postoperative complaints. These are frequently the cause of great distress to patients and it is often the worst memory of their hospital stay ${ }^{1}$. The consequences of prolonged postoperative nausea and vomiting (PONV) range from unexpected admission of day patients, with its economic implications to physical, metabolic and psychologic effect on the patients which slow their recovery and reduce their confidence in future surgery and anaesthesia ${ }^{10}$.

Better anaesthetic technique, identification of precipitating factors, use of new generation of antiemetics and improvement in operative techniques reduce the incidence and severity of PONV has been decreasing over the last 10 years. Despite these changes, there is still unacceptable frequency of PONV with incidences upto 85\% reported in some studies ${ }^{11}$. Watcha and White suggest that the incidence of postoperative nausea and vomiting has remained constant for decades with $20-30 \%$ of patients suffering from these unpleasant side effects ${ }^{3}$. On average $30 \%$ patients suffered from PONV. In UK every year almost 20,00,000 people suffer from PONV, and about 20,000 outpatients need to be admitted following ambulatory surgery due to intractable PONV. Thus PONV is likely to create considerable extra cost for health care system.

The aetiology of PONV is complex and multi factorials. Factors associated with an increased risk of postoperative emesis include age, gender,obesity, a history of motion sickness and/or previous postoperative emesis, anxiety, menstruation, gastroparesis, pain, hypoxia, type of anaesthetic, hypotension and type and duration of the surgical procedure $^{12}$. Patients undergoing laparoscopic surgery are at high risk for postoperative nausea and vomiting ${ }^{3}$. Because most of them are female and due to instrumental manipulation release of humoral substance include- 5 hydroxytryptamine (5-HT) which may stimulate $5-\mathrm{HT}_{3}$ receptor in the afferent vagus nerves triggering the emetic reflex chemoreceptor trigger zone and pneumoperitonium needed for laparoscopy has direct effect on postoperative nausea and vomiting.

Yoshitaka Fujii and Hiroyoshi Tanaka studied the efficacy of the selective 5-hydroxytryptamine receptor antagonist Granisetron with that of the traditional antiemetics droperidol and metoclopramide in the treatment of established PONV after laparoscopic surgery ${ }^{13}$. In this prospective studies, they used injection Granisetron (40ìg/kg)IV, croperidol 20ìg/ $\mathrm{kgIV}$ or Metoclopramide $(0.2 \mathrm{mg} / \mathrm{kg}) \mathrm{IV}$ on those patients who were experiencing PONV during the first 3 hours after anaesthesia and patients were observed for 24 hours after administration of studied drug.

In their study there were no significant group differences in patient's demographic or surgical characteristics. There was no significant difference in haemodynamic parameters - Pulse, B.P and saturation of arterial oxygen. The number of patients who were emesis free (no nausea, retching or vomiting) was significantly higher in patients who received granisetron $(88 \%, 22 / 25)$, than who received droperidol $(60 \%, 16 / 25, \mathrm{p}=0.047)$ or metoclopramide $(55 \%, 14 / 25, \mathrm{p}=0.013)$.

By comparing with this study, our study found that heart rate difference among the groups at preoperative, intraoperative, postoperative upto 24 hours after recovery were not significant. There was no significant changes in systolic and diastolic pressure among the groups of studied patients. In the present study, there were no significant changes in arterial oxygen saturation in the patients of three study groups. The incidence of nausea in group-I $10 \%$, in group-II $33.3 \%$ and in group-III - $60.0 \%$. In our study, the incidence of emesis free (no nausea) was significantly higher in patients who received granisetron $(90.0 \%, 27 / 30)$ than in those who received ondansetron $(66.7 \%, 20 / 30, \mathrm{p}=0.028)$ or metoclopramide $(40.0 \%, 12 / 30, \mathrm{p}=0.000)$.

The incidence of vomiting in group-I (6.7\%). In groupII (26.7\%) and group-III (53.3\%). In our study, the incidence of vomiting free was significantly higher in patients who received granisetron $(93.3 \%, 28 / 30)$ than in those who received ondansetron $(73.3 \%, 22 /$ $30, \mathrm{p}=0.037)$ or metoclopramide $(46.7 \%, 14 / 30, \mathrm{p}=$ 0.000 ).

Also in the study, granisetron was associated with greater patients satisfaction than ondansetron and metoclopramide $40 \%, 20 \%$ and $10 \%$ of patients, respectively $(p=0.032)$. No need for another rescue antiemetic medication was achieved in $86.7 \%$ of patients with granisetron, $70.0 \%$ with ondansetron and $53.3 \%$ with metoclopramide $(\mathrm{p}=0.02)$ in this study. 
In the present study, 5 patients were excluded as laparoscopic procedures could not succeed and open cholecystectomy were done. To maintain the postoperative analgesia injection pethidine $(1.5 \mathrm{mg} /$ kg.b.wt) was given intramuscularly 8 hourly. Inj. Ketorolac (30mg) given I/M on demand.

In our study, it was a great satisfaction that though injection pethidine was given to all patients of three groups for post operative analgesia and sedation, there was no increase in frequency of nausea and vomiting episodes as its side effects, which were also probably blocked by Inj. Granisetron, Ondansetron and Metoclopramide.

Our result showed that, Injection Granisetron (1mg) administered 10 minutes before reversal of anaesthesia is more effective than Ondansetron and Metoclopramide in the prevention and treatment of postoperative nausea and vomiting after laparoscopic cholecystectomy.

\section{CONCLUSION}

The present study was particularly designed to observe the incidence of nausea and vomiting and requirement of rescue antiemetic in postoperative period and also detect the patients satisfaction by verbal rating scale after 24 hours of surgery. After completion of the study it was found that Granisetron greatly reduced the incidence of postoperative nausea and vomiting, and also the requirement of rescue antiemetic in postoperative period than Ondansetron and Metoclopramide. Patient was satisfied by using this drug. So this present randomized prospective comparative clinical study concluded that Granisetron is more effective in comparison to Ondansetron and Metoclopramide in the prevention and treatment of postoperative nausea and vomiting after laparoscopic cholecystectomy.

\section{REFERENCES}

1. Aitkenhead A.R. Postoperative care. In: Alan R, Aitkenhead, David J. Rowbotham, Graham Smith eds. Textbook of Anaesthsia. Further edition, Churchill Livingstone, Harcourt Publishers Limited 2001, page 541.

2. Gan TJ, Solan F, Dear G. EI-Moalem HE, Lubarisky DA. How much are patients willing to pay to avoid postoperative nausea and vomiting? Anesth Analg 2001; 92: 393-400.

3. Watcha MF, White PF. Post operative nausea and vomiting, its etiology, treatment and prevention. Anaesthesiology 1992, 77; 162-184.

4. Rickford JK, Speedy HM, Tytler, Lim M. Comparative evaluation of general, epidural and spinal anesthesia for extra-corporeal shock wave lithotriopsy. Ann R Coll Surg Engl 1988; 70: 69-71.

5. Vance JP, Neill RS, Norri SW. The incidence and aetiology of postoperative nausea and vomiting in a plastic surgery unit. British Journal, Plastic Surg 26; 336-339.

6. Wilson AJ, Diemunsch P, Lindeque BG et al. Single-dose i.v. granisetron in the prevention of post operative nausea and vomiting. Can J Anaesth 1994; 51: 794-7.

7. Andrews PLR. Physiology of nausea and vomiting. Brit J Anaesthesiol 1992; 69: 2-19.

8. Diemunseh P, Conseiller C, Clyti N et al. Ondansetron compared with metoclopramide in the treatment of established post operative nausea and vomiting. French ondansetron study group. Br J Anaesh 1997; 79: 322-6.

9. Henzi I, Walder B, Tramer MR. Metoclopramide in the prevention of postoperative nausea and vomiting: a quantitative systematic review of randomized, placebo-controlled studies. $\mathrm{Br} \mathrm{J}$ Anaesth 1999; 83: 761-71.

10. Kenny GN. Risk factors for postoperative nausea and vomiting. Anaesthesia 1994; 49: 6-10.

11. Hernandez Conte AT. Postoperative nausea and vomiting: a review of antiemetic pharmacological interventions. Anaesth Pharmacol Physiol Rev 1996; 4: 57-65.

12. Philip BK. Etiologis of postoperative nausea and vomiting. Pharmacy Ther 1997; 22: 18-25.

13. Fujii Y, Tanaka H, Toyooka H. Optimal antiemetic dose of granisetron for preventing postoperative nausea and vomiting. Can J Anaesth 1994; 51: 794-7. 